that many of their ideas were simply displaced, rather than rigorously discredited, and that the baby, as it were, might well have been thrown out with the bathwater. Much in the current psychiatric world view is by no means empirically proven, and research activity may often be driven by reasons other than the pure pursuit of knowledge.

Schizophrenia is a disease of the person, and the bewildering variety of manifestations of what appears to be the same disorder finds a parallel in the paradox of human personality - how can we all be in one sense so very different, and yet at the same time so similar? There is a challenging tradition of psychoanalytic personality theory, often very rigorously formulated (e.g. Bion, 1962). It seems rarely drawn on, or even read, by schizophrenia researchers - the result of a psychiatric orthodoxy imposed most tangibly on trainees by the MRCPsych examination.

Extension of models such as Dr Mortimer's to include a level of mind which can accommodate psychodynamic insight, and its own particular methods of research, and allow interaction with the other approaches, are vital for a creative integration within our profession as a whole. Already there are other dialogues taking place, such as between psychoanalysis and artificial intelligence work (Dahl et al, 1988); it is regrettable that there is a lack of such communication between the psychiatric and psychodynamic thinkers. We need to actively prepare the soil in which a new generation of theories might grow.

It may be that current approaches are sufficient, but, as suggested in Mortimer's article, evidence for this hypothesis is lacking. Indeed, using clinical utility as an outcome measure for research, it might be said that psychodynamic ideas have contributed more to the humane management of people with schizophrenia than X-rays of their heads, no matter how exciting it is to see the pictures.

Bion, W. R. (1962) Learning from Experience. London: Karnac Books.

Dahl, H., Kachele, Н. \& Thoma, H. (1988) Psychoanalytic Process Research Strategies. Berlin: Springer-Verlag.

Warneford Hospital

Christopher MALONeY

Headington

Oxford OX3 $7 J X$

\section{Suicide prevention: fact or fiction}

SIR: We read the pessimistic letter of Michael et al (Journal, June 1992, 160, 867-868) in connection with the efficacy of suicide prevention. The importance of the question, especially in Hungary, forced us to think over this problem. To speak about suicide prevention in general terms is counterproductive. Being psychiatrists we cannot speak about the prevention of suicide of a person who has never been seen by a psychiatrist. The question is whether in everyday care we are able to treat high risk patients successfully or not. Primary depression, especially bipolar disorder, represents the highest suicide risk. Previously we demonstrated that under-referral and underdiagnosis of depression is the main cause of suicide in Hungary, since we found a significant negative correlation between suicide rate and the rate of treated depression across the $\mathbf{2 0}$ different regions of Hungary (Rihmer et al, 1990). On the other hand, it has been demonstrated that after an intensive postgraduate training programme for GPs on the diagnosis and treatment of depression, the suicide rate in the area served by trained GPs dropped significantly (Rutz et al, 1989). However, adequate antidepressant treatment can prevent only the suicide risk connected with the given depressive episode, while only adequate prophylactic treatment can provide long-term results in patients with recurrent mood disorders. Since more than $50 \%$ of those who kill themselves have primary, mostly recurrent, depressive illness (Arató et al, 1988) the correct acute and prophylactic treatment of these patients has particular relevance in suicide prevention.

At least six studies have proved the significant reduction in suicidal behaviour of bipolar depressive patients on prophylactic lithium therapy (see Goodwin \& Jamison, 1990, pp. 237-239 for review).

Investigating retrospectively the suicide behaviour of 36 (30 women and 6 men) out-patients with bipolar I $(n=19)$ and bipolar II $(n=17)$ affective disorder who were on prophylactic lithium therapy for at least two years (maximum: 18 years, mean: 7.2 years) we supported the role of prophylactic lithium therapy in preventing suicide in this patient population. Compared with the pre-lithium period (mean: 7.6 years, range: $0.3-18$ years), during the lithium period (mean: 7.2 years, range: $2-18$ years) there was a significant reduction not only in the number of suicidal patients, but also in the number of suicide attempts ( 15 patients and 25 attempts v. 1 patient and 2 attempts, $P<0.001$ ).

We hope that lithium therapy is not just delaying the suicidal behaviour, so that patients who have not made an attempt for the past 18 years will not make one in the next 18 years either.

Arató, M., Demeter, E., Rihmer, Z., et al (1988) Retrospective psychiatric assessment of 200 suicides in Budapest. Acta Psychiatrica Scandinavica, 77, 454-456. 
GoODWIN, F. K. \& JAMISON, K. R. (1990) Manic-Depressive Illness. New York: Oxford University Press.

RIHMER, Z., BARSI, J., VÉG, K., et al (1990) Suicide rates in Hungary correlate negatively with reported rates of depression. Journal of Affective Disorders, 20, 87-91.

RUTZ, W., WALINDER, J., EBERHARD, G., et al (1989) An educational program on depressive disorders for general practitioners on Gotland: background and evaluation. Acta Psychiatrica Scandinavica, 79, 19-26.

ZOLTÁN RIHMER

Katalin SzÁNTó JUDIT BARSI

National Institute for Psychiatry and Neurology

Budapest

Hungary

\section{Nutmeg or mabi bark?}

SIR: Hassiotis \& Taylor (Journal, September 1992, $161,404-407)$ ascribe a psychotic state in a West Indian woman to the consumption of a large quantity of mabi bark tea. This, they state, is the first such case. They note that large amounts of nutmeg (Myristica fragrans) were consumed simultaneously, but this was not discussed as a cause of psychosis by the authors. This is interesting when one is dealing with a 'first'.

Myristicin comes from nutmeg tree oil. In 1576, Lobelius (O'Shea, 1979) wrote of poisoning by nutmeg in a pregnant woman who became intoxicated and "ran wild into the forest". The victim is more usually visually hallucinated, and severe depersonalisation is common. Incidentally, nutmeg has been advocated as an aphrodisiac.

Surely, nutmeg is a more likely cause of this woman's illness.

O'ShEA, B. (1979) Drug abuse through history: the interaction between man and illegal drugs - part one. Irish Medical Times, December 14.

\section{Newcastle Hospital}

Greystones

Co. Wicklow

Ireland

\section{A HUNDRED YEARS AGO}

\section{Retrospect of criminal anthropology. By Havelock Ellis. A Museum of Psychiatry and Criminology}

The deeply interesting and instructive Museum of Criminal Anthropology, founded by Lacassagne in the noble university on the banks of the Rhone, is well known to all medical visitors to Lyons. It is now proposed by the Faculty of Medicine at Turin to establish a museum somewhat similar in character, though of wider scope, at the university with which Lombroso has so long been connected. All the material, so far as it can be collected, for the study of the causes, symptoms, and therapeutics of insanity and criminality will here be brought together. The medical man, the lawyer, and the philosopher will be able to examine the "palimpsests" of the asylum and the prison, the data concerning the aetiology of crime and mental perturbations, the geography of crime, etc., and the skeletons and brains of the insane and criminal will demonstrate the close connection between mental aberrations and corporal abnormalities. Such a museum must form a most valuable source of instruction in psychiatry, and it is to be hoped that the initiative of France and Italy may before long be followed in England. I may add that a Museum of Psychology - not of morbid psychology especially-was founded a few years since at Florence by Professor Mantegazza.

\section{Reference}

Journal of Mental Science, January 1893, 39, 134.

Researched by Henry Rollin, Emeritus Consultant Psychiatrist, Horton Hospital, Epsom, Surrey 